\title{
Abnormal level of paxillin in cervical cancer cells is involved in tumor progression and invasion
}

\author{
Hongqing $\mathrm{Gu}^{1 \otimes}$ and Jing Wen ${ }^{2}$ \\ 1Department of Gynecology, Baodi District People's Hospital, Tianjin, 301800, China; 2Department of Women's Insurance Guidance, Women's \\ And Children's Health Center, Tianjin, 300070, China
}

\begin{abstract}
Human papillomavirus (HPV) is the primary causative agent for the uterine cervical cancer. The expression of oncoproteins E6/E7 promotes apoptosis inhibition and increases the risk of cervical cancer progression. Some research reported that elevated expression of paxillin (PXN) stimulated cancer growth and invasion. However, the clinical significance of PXN in cervical cancer has not been well characterized so far. We found that PXN mRNA expression and protein level are significantly upregulated in cervical cancer cells compared to adjacent normal cells. Furthermore, the paxillin over-expression was correlated with potential of tumorigenesis and invasion. Cervical cancer cells with increased paxillin expression had an ability to form more tumor clones and were characterized by higher invasiveness as well. Therefore, our findings suggest that paxillin may act as an important prognostic factor for cervical cancer patients as it promotes tumor regeneration and invasion.
\end{abstract}

Keywords: cervical cancer, HPV, focal adhesion, paxillin, cancer invasion

Received: 01 June, 2020; revised: 27 August, 2020; accepted: 07 September, 2020; available on-line: 20 February, 2021

هe-mail: ghq001979@163.com

Abbreviations: HPV, Human papillomavirus; PXN, paxillin; $\mathrm{pRB}$, protein retinoblastoma; PFA, paraformaldehyde

\section{INTRODUCTION}

Cervical cancer is the second common cancer among the gynaecological malignancies worldwide. Human papillomavirus (HPV) infection is the key etiological agent for cervical cancer development (Parkin et al., 2002), which accounts for 10-15\% of cancer worldwide (Zur Hausen et al., 1991). The most important and frequent types of HPVs are HPV-16 and HPV-18. Both are highrisk types causing neoplastic lesions which are responsible for $80 \%$ of cervical cancer progression (Munoz et al., 2006 and zur Hausen et al., 2009). The incidence of deaths due to the HPV-related cancers in women is 1/10 (Scheurer et al., 2005). HPV-16 contains 7900 bp long double-stranded circular DNA, which exists episomally in the nucleus of the infected cell to complete the life cycle of the virus (Stubenrauch et al., 1999). There are three coding regions in the genome namely early, late and long. During the virus life cycle, the proteins coded by the early region such as E1 to E7 are expressed early, potentially involved in host cell proliferation and cell survival (Weyn et al., 2011). After HPV infection, the two major viral oncoproteins E6 and E7 are able to interact with tumor suppressor $\mathrm{p} 53$ protein and factors of apoptotic/growth signaling pathways and thus promote malignant transformation, proliferation and immortalization (Bedel et al., 1987 and Brooks et al., 2005). This is achieved by binding of E6 protein to the p53 which results in the accelerated degradation of $\mathrm{p} 53$ through its association with E3 ubiquitin ligase. The HPV-16 infection and expression of its oncoproteins E6 (Werness et al., 1990) and E7 were shown to be involved in the activation of cell cycle program by the inactivation of tumor suppressor protein retinoblastoma (pRB) (Song et al., 1997). The HPV-16 infection and expression of its oncoproteins (E6 and E7) were also reported in the progression and metastasis of cervical cancer (Bosch et al., 1995).

Tumor metastasis is a complicated process by which the cancer cells exit the primary site and create new tumors in different parts of the body as secondary sites. Some research reported that scaffold protein paxillin plays a major role in tumor cell adhesion and migration. Paxillin acts as an adapter protein and is involved in a wide range of functions such as cell proliferation, motility, survival, metastasis, tissue remodelling and matrix organization by co-ordinating different signals from integrins, cell surface and growth receptors (Turner et al., 2000; Schaller et al., 2001; Brown et al., 2004). By proteinprotein interactions and binding to adhesion molecules such as actin and integrins, paxillin induces cytoskeletal rearrangements and thus ultimately causes migration and metastasis of bone, prostate, lung and colorectal cancer (Hagel et al., 2002; Bokobza et al., 2010; Sen et al., 2012; Chen et al., 2013; Zheng et al., 2018). Phosphorylation of PXN (Tyr118) was found to be a major factor involved in the invasiveness of AGS cells (Li et al., 2009). In addition, paxillin acts as a docking site for the oncoproteins such as E6 and v-Src, which interfere with the signalling pathways crucial for cell growth and migration (Turner, 2000). Therefore, in the present study, we evaluated PXN mRNA and protein expression in five different cervical cancer samples and compared it to the adjacent control samples. Furthermore, the tumorigenic and invasion potential of paxillin-expressing cancer cells was also assessed.

\section{MATERIALS AND METHODS}

\section{Sample collection}

The cervical cancer biopsies were obtained from the patients $(n=15)$ at the time of surgery in the Gynaecology Department at our hospital. We also collected the non-malignant cervical tissues $(n=15)$ after getting approval from the patients. Cervical cancer patients details: High grade; well-differentiated squamous cell carcinoma 
(WDSCC). Both normal and cervical cancer tissues undergone histopathological examination by haematoxylineosin staining. The tissues were then washed in ice-cold PBS, dried and frozen in liquid nitrogen as described previously (Pillai et al., 1998).

The obtained cancer and the corresponding control tissues were thoroughly washed with PBS solution containing antibiotics and incubated overnight in DMEM/ F12 (GIBCO) with penicillin $(500 \mathrm{U} / \mathrm{mL}$ ) and streptomycin $(500 \mu \mathrm{g} / \mathrm{mL})$. Tissues were enzymatically digested for $1 \mathrm{~h}$ in PBS solution containing $1.5 \mathrm{mg} / \mathrm{mL}$ of collagenase and $20 \mu \mathrm{g} / \mathrm{mL}$ of hyaluronidase. Cell monolayers were prepared and serially passaged. Cell culture was performed in T-75 flasks or Corning cell culture dishes in DMEM with $10 \% \mathrm{FBS}$ and antibiotics at $37^{\circ} \mathrm{C}$ in a humidified $5 \% \mathrm{CO}_{2}$ and $95 \%$ air atmosphere.

\section{RT-PCR analysis}

By using RNAeasy kit from Qiagen, total RNA extraction was performed according to the manufacturer's protocol and RT-PCR was performed in Biorad iCycler machine. The primers sequences were used as mentioned previously (Chen et al., 2013; Yang et al., 2015). The following parameters were employed for RT-PCR: initial denaturation $95^{\circ} \mathrm{C}$ for $10 \mathrm{~min}$, followed by $50 \mathrm{cy}$ cles of denaturation at $95^{\circ} \mathrm{C}$ for $10 \mathrm{~s}$, annealing at $58^{\circ} \mathrm{C}$ for $15 \mathrm{~s}$, and extension at $70^{\circ} \mathrm{C}$ for $15 \mathrm{~s}$. The amplicons were visualized by $2 \%$ agarose gel electrophoresis and the relative mRNA expression levels were normalized to the housekeeping gene GAPDH.

\section{Analysis of telomerase expression}

We used a modified TRAP (Telomerase Repeat Amplification Protocol) method and the assay was performed as described (Yang et al., 2015) to detect telomerase activity.

\section{Transient transfection}

Cells were seeded into a 6 -well plate with a density of $1 \times 10^{6}$ cells/well. After $24 \mathrm{~h}$ incubation transient transfection was performed. To $200 \mu \mathrm{L}$ of Opti-MEM (Invitrogen) $4 \mu \mathrm{L}$ of transfection reagent Lipofectamine and $3 \mu \mathrm{g}$ of paxillin $\mathrm{m}$-GFP plasmid DNA were added and incubated at room temperature. After 15 minutes of incubation, the reaction mixture was added to the cells. After $24 \mathrm{~h}$ of incubation, the cells were prepared for further experiments. The paxillin $\mathrm{m}$-GFP plasmid was obtained from Dr Xang laboratory, Xinjiang Medical University.

\section{Immunostaining}

Cells grown on poly-L-Lysine-coated coverslips for $24 \mathrm{~h}$ were fixed in $4 \% \mathrm{PFA}$ (paraformaldehyde) in $1 \times$ PBS for $5 \mathrm{~min}$ at room temperature. The cells were then incubated with $0.1 \mathrm{M}$ glycine for $5 \mathrm{~min}$, washed with PBS and incubated with FITC-conjugated anti-paxillin antibody for 30 minutes. The unbound antibodies were removed by further wash with PBS and coverslips were mounted on the slides and sealed. Cells were analyzed using a confocal microscope under $60 \mathrm{x}$ objective.

\section{Western blot analysis}

Protein extraction and separation was performed as previously (Teng et al., 2010). Primary antibodies: rabbit anti-paxillin, 1:500 (Cell Signaling) and mouse anti-GAPDH, 1:1000 (ProteinTech) were used.

\section{In vitro cell culture assays}

Soft agar assay. Cells were cultured in 6-well plates with a range of $2 \times 10^{5}$. The bottom surface of the 6 well plates was covered with $2 \mathrm{~mL}$ of $6 \%$ agar containing: DMEM/F12 and 10\% FBS. After solidification, again $2 \mathrm{~mL}$ of $0.3 \%$ agar mixture containing DMEM/F12 and $10 \%$ FBS was poured over it, incubated for 3 weeks at $37^{\circ} \mathrm{C}$. Finally, crystal violet $(0.005 \%)$ staining was performed to visualize and count the colonies.

Matrigel invasion assay was performed according to the protocol described previously (Ho et al., 2007).

\section{Statistical analysis}

The values presented are mean \pm S.D. and Student's $t$-test was performed to compare the differences. All $P$-values mentioned are 2 -sided and the $P$-value lower than 0.05 (significant) and 0.01 (highly significant) were considered as statistically significant.

\section{RESULTS}

\section{Cervical cancer samples were positive for E6 and E7}

The surgically obtained cervical cancer (S1, S2, S3, S4, S5) and normal tissue samples (designed as C) were subjected to DNA isolation and the DNA integrity was checked with $\beta$-globin primers by PCR amplification. The integrity of the entire amplified DNA sequence was good (550 bp). Further, the intact DNA samples underwent PCR amplification with HPV, HPV-16, E6 and E7 consensus primers. We observed that almost all cervical cancer DNA samples were HPV- (440 bp) and HPV-16(210 bp) positive (Fig. 1A). Further, these DNA samples showed the expression of oncogenes E6 (514 bp) and E7 (297 bp). However, the control samples were negative for the HPV, HPV-16 and oncogenes. Out of 5 samples, 4 DNA samples showed higher E6 expression whereas the S2 sample alone showed moderate positivity for E6 (Fig. 1A). The amplicon size of all the PCR products was compared with $1 \mathrm{~kb}$ DNA ladder. Figure 1B presents the quantitative graph representing the number of samples with proper DNA integrity and oncogenes expression. Importantly, we also found enhanced expres-
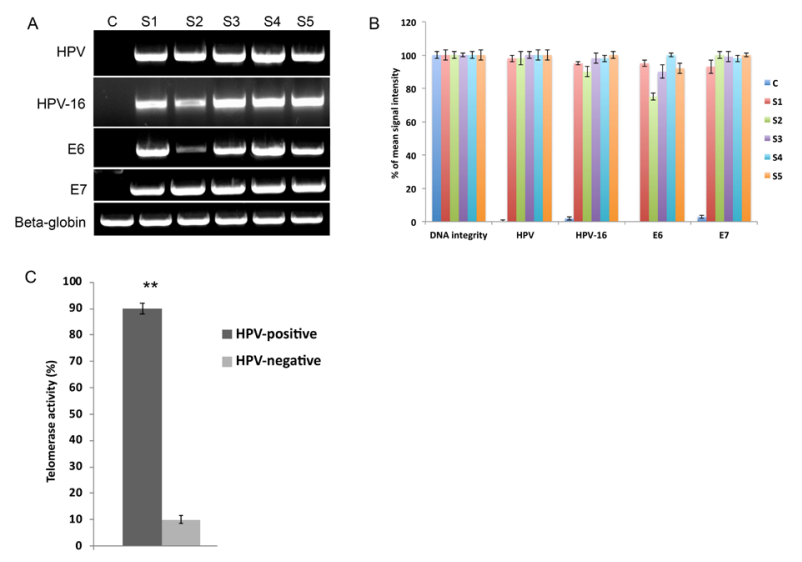

Figure 1. Assessment of human papillomavirus (HPV) presence and oncogenes expression in cervical cancer samples.

PCR amplification (A) and representative graph (B) showing the samples positivity towards HPV, HPV-16, and E6 and E7 genes. (C) Telomerase expression in control and cervical cancer tissues. The values plotted in the graph are the average of three independent experiments. Error bar is the value of standard deviation. ${ }^{* *} P<0.01$. 


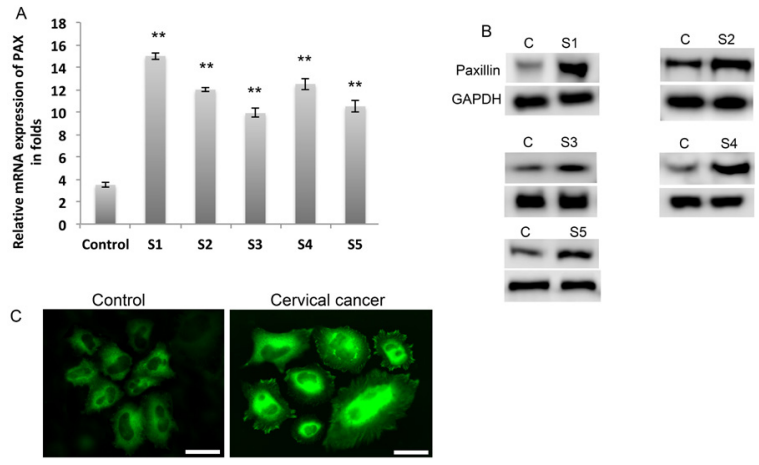

Figure 2. Analysis of PAX expression in control and cervical cancer cells.

RT-PCR (A) and Western blot (B) analysis showing a 4-fold increase in expression of $P A X$ gene and paxillin protein in cancer cells, respectively. (C) Immunocytochemical paxillin staining showing increased signal in cervical cancer cells in comparison to normal cells. The scale bar represents $11 \mu \mathrm{m}$.

sion of telomerase in all the HPV-positive cervical cancer samples in comparison to the normal tissue (Fig. 1C, $* * P<0.01)$. Telomerase plays a major role in cellular immortality and therefore shortening of telomeres correlates with cellular senescence. Our results confirmed that $\mathrm{HPV}$ infection and oncogene expression predominantly contributed to cervical cancer development.

\section{Cervical cancer cells showed up-regulated paxillin expression}

Paxillin can promote tumor cell migration and invasion (Hagel et al., 2002; Li et al., 2009; Bokobza et al., 2010; Sen et al., 2012; Zheng et al., 2018). Therefore, we have examined all the isolated cervical cancer samples for paxillin expression. Using RT-PCR and western blot analysis, we found that the relative mRNA expression level for PAX gene was increased and consequently the paxillin protein level also was enhanced in all the cervical cancer cells obtained from 5 different samples (Fig. 2A and $2 \mathrm{~B}$ ). The mRNA and protein expression level of paxillin was significantly higher in comparison to the adjacent control cells. We further investigated the staining pattern of paxillin in the control and cervical cancer cells. The immunostaining showed an enhanced expression of paxillin in cervical cancer cells with much stronger signal intensity than in the control cells (Fig. 2C).

\section{Enhanced PAX expression promotes in vitro tumor formation and invasion}

As all the cervical cancer samples showed elevated paxillin expression, all of them were subjected to clone formation assay. Figure $3 \mathrm{~A}$ is the representative picture showing that cervical cancer cells with higher paxillin expression formed remarkably more colonies on soft agar plate than the control cells. The relative number of clones generated by paxillin-over-expressing cervical cancer cells was significantly higher as presented in the quantification graph (Fig. $3 \mathrm{~B}, * P<0.04$; $* * P<0.01$ ). We further performed a confirmatory experiment, where the control cells were transiently transfected with PAXmGFP overexpression cassette and again clone formation efficiency was evaluated. We observed that PAXmGFP transfected cells formed more colonies on soft agar plate (Fig. 3C \& 3D), compared to the cells transfected with empty vector. In addition, our Matrigel invasion evaluation showed that paxillin over-expressing
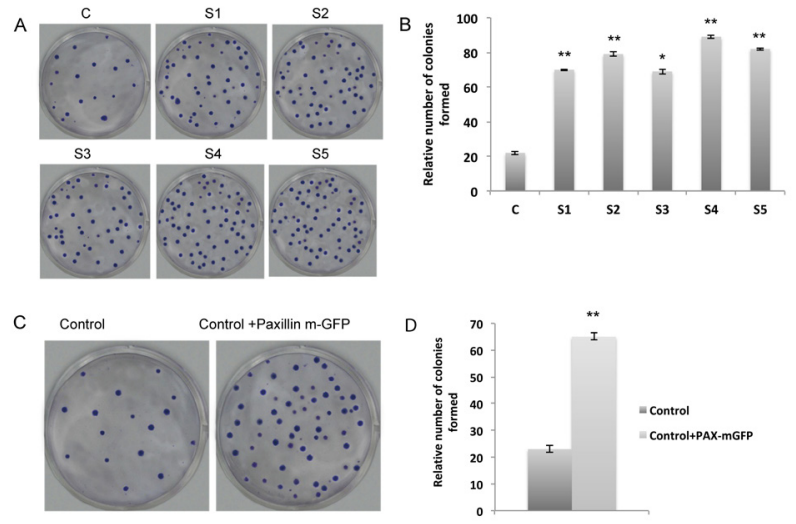

Figure 3. Cells with upregulated PAX are highly clonogenic.

Soft agar assay (A and $\mathbf{C}$ ) comparing the efficiency of clone formation between control, cervical cancer cells and PAX-mGFP transfected cells. (B and $\mathbf{D})$ are the representative quantifications showing the total number of generated colonies. The values presented in the graph are the average values from two independent experiments. Error bar represents standard deviation. ${ }^{*} P<0.05$; ${ }^{* *} P<0.01$.

cervical cancer cells had a high capability of invading the Matrigel (Fig. 4, $* * P<0.01$ ) and thus confirmed the importance of paxillin in the tumor initiation, progression and invasion.

\section{DISCUSSION}

The malignancy of the cervix is called uterine cervical cancer and there are mainly two types of the disease: adenocarcinoma which develops from the endocervix mucus-producing gland cells and squamous cell carcinoma which originates from the squamous cells of the ectocervix. More than $90 \%$ of the cervical cancers worldwide are associated with HPV infection, which is the primary risk factor of cervical cancer (Parkin, 2002; zur Hausen, 1991; Muñoz et al., 2003). The oncoproteins E6 and E7 produced by HPV subtypes 16/18 were shown to inhibit the tumor suppressor genes $\mathrm{p} 53$ and $\mathrm{Rb}$, respectively (Yang et al., 2015). As a result, the regulation of apoptosis and cell cycle events is interrupted which leads to compromised apoptosis, rapid proliferation and neoplastic transformation in the affected cells. Therefore, the prevalence of E6 and E7 are crucial for the pathogenesis of HPV-related cervical cancer, as they are involved in the immortalization and malignant transformation of the HPV-infected cells (Kaufman et al., 1997; Zehbe et al., 1997). It was reported that $64 \%$ of cervical cancer cases are predominantly associated with HPV-16 subtype

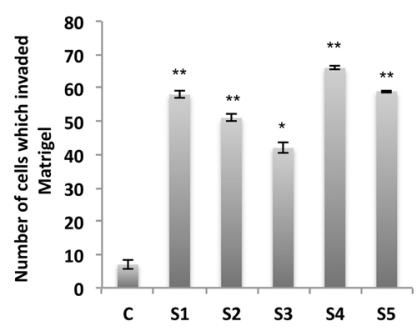

Figure 4. Matrigel invasion assay showing that $P A X$ over-expressing cervical cancer cells are highly capable of invading the Matrigel.

The values presented are the averages from three independent experiments. Error bar represents standard deviation. 
(Das et al., 1992). In our study, all the surgically obtained the cervical cancer samples contained HPV-16 subtype and almost all these biopsies were characterized by the expression of E6 and E7 oncoproteins. Therefore, the presence of these oncoproteins is more than enough to trigger an uncontrolled cell proliferation by escaping apoptosis and thus increases the risk of cervical cancer progression. The accelerated cell proliferation and compromised apoptosis are the results of the inactivation of p53 and pRb by E6 and E7, respectively (Werness et al., 1990; Yang et al., 2015). Studies reported that differential telomerase expression correlates with different grades of cancer (Das et al., 1992; Yang et al., 2015). In line with the previous findings, we observed significantly increased telomerase expression in HPV-16-infected cervical cancer biopsies. Therefore, we speculate that the presence of HPV-16 may be associated with an enhanced expression of telomerase in cancer tissues.

Paxillin is a multifunctional focal adhesion adapter protein and plays an important role in cancer growth and metastasis by integrating different signalling and growth factors involved in the cell migration (Das et al., 1992). Different studies in prostate, lung and bone cancer showed that paxillin was highly expressed in cancer tissues when compared to the normal tissues. This significantly overexpressed paxillin promoted tumor cell proliferation, migration and invasion (Hagel et al., 2002; Chen et al., 2013; Zheng et al., 2018). However, the clinical significance of paxillin in cervical cancer is still unknown. We found significantly higher mRNA expression and protein levels of paxillin in cervical cancer tissues than in normal tissues. Paxillin is a focal adhesion protein which co-ordinates the multiple signals between integrins and extracellular matrix to promote cytoskeleton remodelling for cell adhesion and migration (Turner, 2000; Li et al., 2009; Bokobza et al., 2010). The increased expression of paxillin may pave the way for increased cell adhesion, motility, proliferation and invasion. Consequently, our data showed that paxillin over-expressing cervical cancer cells have a high capability of Matrigel invasion. The in vitro colony formation assay further confirmed that over-expression of paxillin promotes cancer colony formation. In a control experiment, we transiently transfected normal cervical cells with paxillin-mGFP over-expression cassette. Again, the transfected cells showed higher colony formation potential when compared to the control which contained only the empty vector. Therefore, the underlying mechanism of paxillin-mediated tumorigenesis and invasion needs to be elucidated in the future. Another study revealed that phosphorylation of paxillin is in cell adhesion. The overexpression of paxillin correlated with enhanced expression of protein tyrosine phosphatase (LMWPTP), tumor recurrence and poor survival of patients (Ruela-de-Sousa et al., 2016). In gastric cancer, upregulated paxillin was associated with aggressive tumor regeneration, metastasis and overall poor survival (Chen et al., 2013; Zheng et al., 2018). In addition, knockdown of PXN in gastric cancer tissue/cell lines inhibited cancer cells proliferation and migration, thus confirming the role of paxillin in gastric cancer progression (Chen et al., 2013).

In summary, we demonstrated that the presence of high-risk HPV-16 and its oncoproteins (E6/E7) is involved in cervical cancer progression and invasion. Further findings suggest that paxillin may act as an important prognostic factor for cancer patients and plays a crucial role in tumor regeneration. Hence, these findings would definitely helps to reveal the factors and other signaling pathways involved in the paxillin phospho- rylation/paxillin-mediated uterine cervix tumorigenesis. Elucidating such a detailed mechanism would certainly improve the cancer treatment approaches in order to increase the survival of the patients.

\section{Conflict of interest}

All authors declare no conflict of interest.

\section{REFERENCES}

Bedell MA, Jones KH, Laimins LA (1987) The E6-E7 region of human papillomavirus type 18 is sufficient for transformation of NIH 3T3 and rat-1 cells. J Virol 61: 3635-3640

Bokobza SM, Ye L, Kynaston HG, Jiang WG (2010) Growth and differentiation factor-9 promotes adhesive and motile capacity of prostate cancer cells by up-regulating FAK and Paxillin via Smad dependent pathway. Oncol Rep 24: 1653-1659. https://doi. org/10.3892/or_00001030

Bosch FX, Manos MM, Muñoz N, Sherman M, Jansen AM, Peto J, Schiffman MH, Moreno V, Kurman R, Shan KV (1995) Prevalence of human papillomavirus in cervical cancer: a worldwide perspective. International Biological Study on Cervical Cancer (IBSCC) Study Group. J Natl Cancer Inst 87: 796-802. https://doi. org/10.1093/jnci/87.11.796

Breslow RA, Shay JW, Gazdar AF, Srivastava S (1997) Telomerase and early detection of cancer: a National Cancer Institute Workshop. Nat Cancer Inst 89: 618-623. https://doi.org/10.1093/jnci/89.9.618

Brooks H, Lebleu B, Vivès E (2005) Tat peptide-mediated cellular delivery: back to basics. Adv Drug Deliv Rev 57: 559-577. https://doi. org/10.1016/j.addr.2004.12.001

Brown MC, Turner CE (2004) Paxillin: adapting to change. Physiol Rev 84: 1315-1339. https://doi.org/10.1038/35046659

Chen DL, Wang ZQ, Ren C, Zeng ZL, Wang DS, Luo HY, Wang F, Qiu MZ, Bai L, Zhang DS, Wang FH (2013) Abnormal expression of paxillin correlates with tumor progression and poor survival in patients with gastric cancer. J Transl Med 11: 277. https://doi. org/10.1186/1479-5876-11-277

Das BC, Sharma JK, Gobalakrishna V, Das DK, Singh V, Gissman L, zur Hausen H, Luthra UK (1992) A high frequency of human papillomavirus DNA sequences in cervical carcinomas of Indian women as revealed by Southern blot hybridization and polymerase chain reaction. J Med Virol 36: 239-245. https://doi.org/10.1002/ jmv.1890360402

Hagel M, George EL, Kim A, Tamimi R, Opitz SL, Turner CE, Imamoto A, Thomas SM (2002) The adaptor protein paxillin is essential for normal development in the mouse and is a critical transducer of fibronectin signaling. Mol Cell Biol 22: 901-915. https:// doi.org/10.1128/mcb.22.3.901-915.2002

Ho MM, Ng AV, Lam S, Hung JY (2007) Side population in human lung cancer cell lines and tumors is enriched with stem-like cancer cells. Cancer Res 67: 4827-4833. https://doi.org/10.1158/0008-5472. CAN-06-3557

Kaufman RH, Adam E, Icenogle J, Lawson H, Lee N, Reeves KO, Irwin J, Simon T, Press M, Uhler R, Entman C (1997) Relevance of human papillomavirus screening in the management of cervical intraepithelial neoplasia. Am J Obstet Gynecol 176: 87-92. https://doi. org/10.1016/s0002-9378(97)80017-8

Li D, Ding J, Wang X, Wang C, Wu T (2009) Fibronectin promotes tyrosine phosphorylation of paxillin and cell invasiveness in the gastric cancer cell line AGS. Tumori 95: 769-779.

Muñoz N, Bosch FX, De Sanjosé S, Herrero R, Castellsagué X, Shah KV, Snijders PJ, Meijer CJ (2003) Epidemiologic classification of human papillomavirus types associated with cervical cancer. $N$ Engl J Med 348: 518-527. https://doi.org/10.1056/NEJMoa021641

Munoz N, Castellsagué X, de González AB, Gissmann L (2006) HPV in the etiology of human cancer. Vaccine 24: S1-S0. https://doi. org/10.1016/j.vaccine.2006.05.115

Parkin DM, Bray F, Ferlay J, Pisani P (2005) Global cancer statistics, 2002. CA: Cancer J Clin 55: 74-108. https://doi.org/10.3322/canjclin. 55.2.74

Pillai MR, Lakshmi S, Sreekala S, Devi TG, Jayaprakash PG, Rajalakshmi TN, Devi CC, Nair MK, Nair MB (1998) High-risk human papillomavirus infection and E6 protein expression in lesions of the uterine cervix. Pathobiology 66: 240-246. https://doi. org/10.1159/000028029

Ruela-de-Sousa RR, Hoekstra E, Hoogland AM, Queiroz KC, Peppelenbosch MP, Stubbs AP, Pelizzaro-Rocha K, van Leenders GJ, Jenster G, Aoyama H, Ferreira CV (2016) Low-molecular-weight protein tyrosine phosphatase predicts prostate cancer outcome by increasing the metastatic potential. Eur Urol 69: 710-719. https:// doi.org/10.1016/j.eururo.2015.06.040 
Schaller MD (2001) Paxillin: a focal adhesion-associated adaptor protein. Oncogene 20: 6459-6472. https://doi.org/10.1038/ sj.onc. 1204786

Scheurer ME, Tortolero-Luna G, Adler-Storthz K (2005) Human papillomavirus infection: biology, epidemiology, and prevention. Int J Gynecol Cancer 15: 727-746. https://doi.org/10.1111/j.15251438.2005.00246.x

Sen A, De Castro I, DeFranco DB, Deng FM, Melamed J, Kapur P, Raj GV, Rossi R, Hammes SR (2012) Paxillin mediates extranuclear and intranuclear signaling in prostate cancer proliferation. J Clin Invest 122: 2469-2481. https://doi.org/10.1172/JCI62044

Song YS, Kee SH, Kim JW, Park NH, Kang SB, Chang WH, Lee HP (1997) Major sequence variants in E7 gene of HPV type 16 from cervical cancerous and Non cancerous lesions of Korean women. Gynecol Oncol 66: 275-281. https://doi.org/10.1006/gyno.1997.4756

Stubenrauch F, Laimins L (1999) Human papillomavirus life cycle: active and latent phases. In Seminars in cancer biology, vol 9, no 6, pp 379-386. Academic Press. https://doi.org/10.1006/ scbi.1999.0141

Teng KY, Qiu MZ, Li ZH, Luo HY, Zeng ZL, Luo RZ, Zhang HZ, Wang ZQ, Li YH, Xu RH (2010) DNA polymerase eta protein expression predicts treatment response and survival of metastatic gastric adenocarcinoma patients treated with oxaliplatin-based chemotherapy. J Transl Med 8: 126. https://doi.org/10.1186/1479-5876-8126

Turner CE (2000) Paxillin and focal adhesion signalling. Nat Cell Biol 2: E231-E236. https://doi.org/10.1038/35046659
Turner CE (2000) Paxillin interactions. I Cell Sci 113: 4139-4140

Werness BA, Levine AJ, Howley PM (1990) Association of human papillomavirus types 16 and $18 \mathrm{E} 6$ proteins with p53. Science 248: 76-79. https://doi.org/10.1126/science.2157286

Weyn C, Vanderwinden JM, Rasschaert J, Englert Y, Fontaine V (2011) Regulation of human papillomavirus type 16 early gene expression in trophoblastic and cervical cells. Virology 412: 146-155. https://doi.org/10.1016/j.virol.2010.12.056

Yang X, Lu L (2015) Expression of HPV-16 E6 protein and p53 inactivation increases the uterine cervical cancer invasion. Drug Res (Stuttg) 65: 70-73. https://doi.org/10.1055/s-0034-1372614

Zehbe I, Wilander E (1997) Human papillomavirus infection and invasive cervical neoplasia: A study of prevalence and morphology. J Pathol 181: 270-275. https://doi.org/10.1002/(SICI)10969896(199703)181:3<270::AID-PATH767>3.0.CO;2-R

Zheng QS, Chen SH, Wu YP, Chen HJ, Chen H, Wei Y, Li XD, Huang JB, Xue XY, Xu N (2018) Increased Paxillin expression in prostate cancer is associated with advanced pathological features, lymph node metastases and biochemical recurrence. J Cancer 9: 959967. https://doi.org/10.7150/jca.22787

zur Hausen H (1991) Viruses in human cancers. Science 254: 1167 1173. https://doi.org/10.1126/science.1659743

zur Hausen H (2009) Papillomaviruses in the causation of human cancers - a brief historical account. Virology 384: 260-265. https://doi. org/10.1016/j.vaccine.2006.05.115 